\title{
Efeito do hipotireoidismo materno na expressão espaço-temporal de mediadores imunológicos e população de células natural killers na decídua e na glândula metrial de ratas
}

[Effect of maternal hypothyroidism on the spatiotemporal expression of immunological mediators and population of Natural Killers cells in decidua and metrial gland of rats]

\section{C.A. Souza ${ }^{1}$, J.F. Silva ${ }^{2}$, N.M. Ocarino ${ }^{1}$, C.L.R. Silva ${ }^{1}$, L.A. Gomes ${ }^{1}$, G.S.M. Assunção ${ }^{1}$, C.M.O. Silva', K.P. Oliveira ${ }^{1}$, R. Serakides ${ }^{1 *}$}

\author{
${ }^{1}$ Escola de Veterinária - Universidade Federal de Minas Gerais - Belo Horizonte, MG
}

${ }^{2}$ Universidade Estadual de Santa Cruz - Ilhéus, BA

\section{RESUMO}

Estudou-se o efeito do hipotireoidismo materno na expressão espaço-temporal de mediadores imunológicos e na população de células natural killers $(\mathrm{NK})$ na decídua e na glândula metrial de ratas durante a gestação. Avaliou-se a detecção imunoistoquímica de interferon $\gamma$ (IFN $\gamma$ ), do fator inibidor de migração (MIF), da interleucina 15 (IL15), do óxido nítrico sintase induzível (iNOS), a marcação com lectina DBA para evidenciação das células NK uterinas $\mathrm{DBA}^{+}$e a expressão gênica de Ifny e Nos2. O hipotireoidismo aumentou o iNOS aos sete dias, a IL15 e o MIF aos 10 e 12 dias, o IFN $\gamma$ e o MIF aos 14 DG e a expressão dos transcritos gênicos para iNos aos 12 e 19 dias e para Ifny aos 14 DG. O hipotireoidismo reduziu a imunomarcação de MIF e lectina DBA aos sete dias, lectina DBA aos 10 e 14 DG, IFN $\gamma$ aos 12 dias, e a expressão de Ifn $\gamma$ aos 10 e 19 DG e de iNOS aos 12, 14 e 19 DG, bem como reduziu seus transcritos gênicos aos 10 e 14 DG. Conclui-se que o hipotireoidismo compromete o perfil imunológico na interface materno-fetal ao longo da gestação, particularmente por reduzir o fator anti-inflamatório iNOS e a população de células uNK DBA ${ }^{+}$.

Palavras-chave: hipotireoidismo, decídua, glândula metrial, imunologia

\section{ABSTRACT}

The goal of this study was to evaluate the effect of maternal hypothyroidism on the spatiotemporal expression of immunological mediators and population of Natural Killers cells in decidua and metrial gland of rats. Interferon gamma (IFN $\gamma$ ), migration inhibitory factor (MIF), interleukin 15 (IL15), inducible nitric oxide synthase (iNOS), and DBA-Lectin labeling for evidence of $u N K \mathrm{DBA}^{+}$cells in decidua and genetic expression of Ifn $\gamma$ and iNos by real-time RT-PCR were evaluated. Hypothyroidism increased protein expression of iNOS at 7 days, IL15 and MIF at 10 and 12 days, IFNy and MIF at 14 DG in the decidua and/or metrial gland and the gene transcripts for iNOS at 12 and 19 days and for Inf at 14 DG. In addition, hypothyroidism reduced the protein expression of MIF and DBA-Lectin at 7 days, DBA-Lectin at 10 and 14 DG. IFNy at 12 days, and the gene transcript to Ifn $\gamma$ at 10 and 19 DGs. Hypothyroidism also reduced the protein expression of iNOS at 12, 14 and 19 DG and reduced its gene transcripts at 10 and 14 DGs. It is concluded that hypothyroidism compromises the immunology profile at the maternal-fetal interface throughout pregnancy, particularly by reducing the anti-inflammatory factor iNOS and population of $u N K \mathrm{DBA}^{+}$cells.

Keywords: hypothyroidism, decidua, metrial gland, imunology

\section{INTRODUÇÃO}

Na gestação, o processo de decidualização é crucial no estabelecimento da interface maternofetal. Isso porque a decídua promove a troca seletiva de nutrientes e metabólitos entre a mãe e

Recebido em 27 de março de 2018 Aceito em 12 de março de 2019

*Autor para correspondência (corresponding author)

E-mail: serakidesufmg@gmail.com o feto (Plaisier, 2011; Cha et al., 2012) e fornece um ambiente imunológico que permite a permanência do embrião/feto semialogênico em íntimo contato com o útero (Gellersen et al., 2007; Reynolds et al., 2010). Portanto, para o sucesso da gestação, é fundamental que haja uma interação fisiologicamente coordenada entre a placenta e o útero (Collins et al., 2009), que será orquestrada por hormônios, entre os quais os 
hormônios tireoidianos (Kilby et al., 2005; Twig et al., 2012). Alterações séricas desses hormônios durante a gestação têm resultado em aborto, natimortalidade e restrição do crescimento intrauterino tanto na mulher como nas espécies de animais domésticos (Zhang et al., 2007; Soares et al., 2012).

Durante a decidualização em roedores, as células natural killers uterinas (uNKs) se infiltram no endométrio, a partir do sétimo e oitavo dias de gestação, para coordenar o remodelamento vascular e influenciar o perfil imunológico na interface materno-fetal (Picut et al., 2009; Zhang et al., 2011). Essas células são um tipo de leucócito, com características morfológicas e bioquímicas específicas, que sintetizam uma ampla variedade de citocinas e fatores de crescimento na interface materno-fetal (Ashkar et al., 2003). O recrutamento, a maturação e a diferenciação dessas células são dependentes da síntese de IFN $\gamma$, IL15 e MIF, entre outras. Essas citocinas pró-inflamatórias são sintetizadas por vários tipos celulares presentes na decídua, inclusive pelas próprias uNKs, e desempenham papel importante na resposta imune inata $\mathrm{e}$ adaptativa na interface materno-fetal (Ashkar et al., 2000; Ashkar et al., 2003).

O IFN $\gamma$ estimula a atividade fagocitária dos macrófagos e das células gigantes trofoblásticas contra microrganismos (Ashkar et al., 2000; Silva et al., 2014). A IL15 altera o fenótipo das células NK do interstício uterino e do sangue para o fenótipo das uNKs que estão presentes no endométrio durante a gestação (Kitaya et al., 2003a,b). Além disso, a IL15 aumenta as atividades proliferativa e citolítica das uNKs in vitro (Ye et al., 1996). O MIF estimula a expressão de uma grande variedade de citocinas pró-inflamatórias, como o fator de necrose tumoral (TNF), o IFN $\gamma$, a IL2, a IL6 e a IL8 (Faria et al., 2010), bem como estimula a angiogênese; a proliferação celular suprime a apoptose (Arcuri et al., 2006; Viganò et al., 2007) e reduz a capacidade citolítica das uNKs (Arcuri et al., 2006), antagonizando, portanto, a IL15. Cartwright et al. (1999) demonstraram que a motilidade e a invasão das células trofoblásticas na decídua são altamente dependentes do óxido nítrico sintase induzível (iNOS) sintetizado pelos trofoblastos in vitro, uma citocina anti-inflamatória.
Ratas com hipotireoidismo apresentam redução da expressão de IFN $\gamma$ e TNF $\alpha$ pelas células trofoblásticas dependendo do período gestacional (Silva et al., 2014), enquanto mulheres com hipotireoidismo têm redução da expressão de IL4 e IL10, citocinas anti-inflamatórias, pelas células deciduais (Twig et al., 2012). É importante ressaltar que alteração na população e na atividade citolítica das uNKs no endométrio de mulheres gestantes está associada a complicações gestacionais, como aborto e restrição do crescimento intrauterino (Ashkar et al., 2003) e é modulada pela IL15 (Ye et al., 1996). Além disso, camundongos que não possuem células uNKs são férteis, mas exibem remodelamento vascular uterino inadequado, pobre decidualização e baixo peso fetal (Colucci et al., 2011). Pesquisas já demonstraram que o hipotireoidismo compromete o ambiente antiinflamatório do disco placentário por reduzir a expressão de IL10 e iNOS (Silva et al., 2014). Contudo, ainda não há nenhuma evidência se na decídua de animais com hipotireoidismo ocorre o mesmo efeito. $\mathrm{O}$ que se sabe é que a síntese in vitro de citocinas inflamatórias pelas células deciduais humanas é responsiva à triiodotironina $\left(\mathrm{T}_{3}\right)$ (Vasilopoulou et al., 2014).

Apesar das pesquisas que investigaram os efeitos das disfunções tireoidianas no disco placentário de ratas (Silva et al., 2012; Silva et al., 2014; Silva et al., 2015), a população de células uNKs e a expressão de fatores imunológicos na decídua de animais com hipotireoidismo não têm sido estudadas. Assim, o objetivo deste estudo foi investigar os efeitos do hipotireoidismo na detecção imunoistoquímica das citocinas IFN $\gamma$, IL15, iNOS, MIF e da lectina DBA para avaliação das células uNK e da expressão de transcritos gênicos para Ifn $\gamma$ e iNos na decídua e na glândula metrial de ratas ao longo da gestação.

\section{MATERIAL E MÉTODOS}

Todos os procedimentos experimentais foram aprovados pelo Comitê de Ética em Experimentação Animal da Universidade Federal de Minas Gerais (protocolo nº. 268/2011). Foram utilizadas 72 ratas Wistar, com dois meses de idade, alojadas em caixas plásticas (seis animais/caixa), onde receberam ração comercial (1,4\% de cálcio, $0,60 \%$ de fósforo e $22 \%$ de proteína) e água ad libitum. As ratas foram 
mantidas em regime de 12 horas de luz e 12 horas de escuro. Após um período de 30 dias de adaptação, as ratas foram separadas, ao acaso, em dois grupos: hipotireoideo e controle, sendo cada grupo com 36 animais. $\mathrm{O}$ grupo hipotireoideo recebeu diariamente, por sonda orogástrica, durante cinco dias, 1mg/animal de 6propil-2-tiouracil (Silva et al., 2012), diluído em $5 \mathrm{~mL}$ de água destilada. Os animais do grupo controle receberam água destilada como placebo.

Após cinco dias do início do tratamento, as fêmeas de ambos os grupos foram submetidas à citologia vaginal para acompanhamento do ciclo estral. Nesse mesmo período, seis ratas de cada grupo foram eutanasiadas com sobredose de anestésico para coleta de sangue e dosagem de $\mathrm{T}_{3}$ e $\mathrm{T}_{4}$ livre para confirmação da indução do hipotireoidismo. As ratas em proestro e estro foram alojadas em caixas plásticas com ratos adultos por 12 horas. Após esse período, esfregaços vaginais foram realizados diariamente no início da manhã, a fim de se detectar a presença de espermatozoides, o que confirmava a cópula, e esse dia era designado como dia 0 de gestação. Após a cópula, as ratas foram alojadas em caixas separadas. Os animais dos grupos hipotireoideo e controle continuaram com o tratamento, como descrito acima, até a eutanásia.

No dia 0 e aos 19 dias de gestação, seis ratas de cada grupo foram anestesiadas com cloridrato de xilazina a 2\% (Laboratórios König, Avellaneda Argentina $(5 \mathrm{mg} / \mathrm{kg}$, intramuscular) e quetamina injetável Vetnil - $10 \mathrm{mg} / \mathrm{mL}-$ (Vetecia Laboratórios de Produtos Veterinários Ltda. Louveira - SP, Brasil) (50mg/kg, intramuscular), para coleta de sangue por punção intracardíaca. O sangue foi coletado em tubos com heparina para obtenção do plasma, e este armazenado a $20^{\circ} \mathrm{C}$ para posterior dosagem de tri-iodotironina $\left(\mathrm{T}_{3}\right)$ e tiroxina $\left(\mathrm{T}_{4}\right)$ livre. A dosagem foi realizada pela técnica de quimioluminescência (Access Immunoassay System, Sanofi Diagnostics Pasteur Inc., Chaska, MN, USA), em sistema totalmente automático e de acordo com as recomendações do fabricante dos kits.

Nos dias sete, 10, 12, 14 e 19 de gestação (DG), seis ratas de cada grupo foram eutanasiadas com sobredose de anestésico. Após a eutanásia, o útero contendo a placenta e os fetos foram separados da tuba e dos ovários. Foram retirados aleatoriamente cinco sítios de inserção placentária por rata. Os sítios foram dissecados, e a decídua juntamente com as membranas fetais foram coletadas. As decíduas de três sítios de inserção placentária por rata foram fixadas em paraformaldeído a $4 \%$ por 24 horas. Em seguida, foram processadas pela técnica rotineira de inclusão em parafina e submetidas à microtomia para obtenção de secções de $4 \mu \mathrm{m}$. As secções foram coradas pela hematoxilina-eosina $\mathrm{e}$ submetidas à imunoistoquímica para avaliação da expressão de IFN $\gamma$, iNOS, MIF, IL15 e lectina DBA. Para a realização do RT-PCR em tempo real para os genes Ifn $\gamma$ e iNos, foi coletada somente a região de decídua, juntamente com a glândula metrial de dois sítios da interface materno-fetal por animal, nos períodos de 10, 12, 14 e 19 DG. As amostras foram mergulhadas imediatamente em TRIzol (Invitrogen, Carlsbad, CA, USA), congeladas em nitrogênio líquido e estocadas a $-80^{\circ} \mathrm{C}$, por no máximo duas semanas, até a análise.

Foram utilizados os anticorpos anti-IFN $\gamma$ (1:200) (AB9657, Abcam, Cambridge, UK), anti-iNOS (1:100) (AB15323, Abcam, Cambridge, UK), anti-MIF (1:500) (AB7207, Abcam, Cambridge, UK), anti-IL15 (1:300) (AF447, RD System, Minneapolis, USA) e antilectina DBA (1:300) (L6533-5MG, Sigma, Saint Louis, USA). A técnica realizada foi a da estreptavidina-biotinaperoxidase (Streptavidin Peroxidase, Dako $\mathrm{LSAB}+$ System-HRP, Carpinteira, CA, USA), e a recuperação antigênica foi realizada pelo calor em banho-maria a $98^{\circ} \mathrm{C}$, utilizando-se tampão citrato $(2,1 \mathrm{~g}$ de ácido cítrico em $1 \mathrm{~L}$ de água destilada, ajustando-se o pH em 6,0 com $\mathrm{NaOH}$ a $0,5 \%$ ). As secções histológicas foram incubadas em câmara úmida overnight com o anticorpo primário e por 30 minutos nas etapas de bloqueio da peroxidase endógena, soro de bloqueio (Dako Protein Block Serum-Free Ready-To-Use, Carpinteira, CA, USA) e estreptavidina peroxidase. Os anticorpos primários anti-IFN $\gamma$, anti-iNOS, anti-MIF, anti-IL15 e antilectina DBA foram incubados overnight. A incubação com anticorpo secundário foi realizada por 45 minutos. O cromógeno foi a diaminobenzidina (Dako DAB Substrate Chromogen System, Carpinteira, CA, USA). As secções foram contracoradas com hematoxilina. O controle negativo foi obtido pela substituição do anticorpo primário por soro bloqueio. 
Foi realizada uma avaliação descritiva e quantitativa da detecção imunoistoquímica de IFN $\gamma$, MIF, iNOS, IL15 e lectina DBA nas camadas de decídua mesometrial e antimesometrial aos sete DG, na decídua mesometrial aos 10 DG e na decídua basal e na glândula metrial aos 12, 14 e 19 DG, adjacente ao sítio de inserção placentária. A avaliação quantitativa foi realizada em três sítios de inserção placentária/rata. Uma secção histológica/sítio de inserção placentária foi feita transversalmente, sempre no mesmo ponto, incluindo a decídua e a glândula metrial com seus vasos sanguíneos e o disco placentário, para padronização do local de análise. Para determinar a área de imunomarcação, imagens foram fotografadas com a câmera digital Spot Color Insight (SPOTTM, Sterling Heights, Michigan, USA) acoplada a um microscópio Olympus BX-40. A área de imunomarcação foi determinada pelo WCIF Image $^{\circledR} \quad$ (Media Cybernetics Manufacturing, Rockville, MD, USA). Color deconvolution e thresholding das imagens foram feitos. Os dados de cada decídua foram arquivados, analisados e expressos como área de imunomarcação em pixels.

O mRNA total da região da decídua e da glândula metrial foi extraído usando-se o reagente TRIzol (Invitrogen, Carlsbad, CA, USA) de acordo com as instruções do fabricante. Um total de $1 \mu \mathrm{g}$ de RNA foi utilizado para a síntese de cDNA, utilizando-se o kit SuperScript ${ }^{\circledR}$ III First-Strand Synthesis SuperMix (Invitrogen, Carlsbad, CA, USA). As reações foram realizadas em um termociclador Smart Cycler II (Cepheid Inc., Sunnyvale, CA, USA).

Realizou-se PCR em tempo real com Platinum $^{\circledR}$ $S Y B R^{\circledR}$ Green qPCR SuperMix-UDG (Invitrogen, Carlsbad, CA, USA) no $A B$ The Applied Biosystems $^{\text {TM }}$ ViiA $^{\text {тм }} 7$ system (Applied Biosystems, Life Technologies). Para os controles negativos, utilizou-se o mix de amplificação de DNA completo, e a amostra contendo o cDNAalvo foi substituída por água. As amplificações foram realizadas utilizando-se as condições de ciclagem padrão: ativação da enzima a $95^{\circ} \mathrm{C}$ durante $10 \mathrm{~min}, 40$ ciclos de desnaturação a $95^{\circ} \mathrm{C}$ durante 15 s e pareamento dos primers/extensão a $60^{\circ} \mathrm{C}$ durante $60 \mathrm{~s}$. Para avaliar a linearidade e a eficiência da amplificação por PCR, foram geradas curvas-padrão para todos os transcritos, utilizando-se diluições em série de cDNA. A curva de fusão foi obtida para os produtos de amplificação para determinar as suas temperaturas de fusão. A expressão gênica foi calculada usando-se o método $2^{-\Delta \Delta \mathrm{Ct}}$, em que os valores das amostras foram calculados $\mathrm{e}$ calibrados em relação aos valores do CT de $\beta$ actina. Os primers estão listados na Tab. 1. Todas as análises foram realizadas nas regiões de decídua mais glândula metrial aos 10, 12, 14 e 19 DG.

Tabela 1. Lista de genes e sequência de nucleotídeos dos primers para RT-PCR em tempo real

\begin{tabular}{|c|c|c|}
\hline Genes & Primers & Número de acesso \\
\hline \multirow{2}{*}{ Ifn $\gamma$} & Forward 5'- AGTGCTACACGCCGCGTCTT -3' & \multirow{2}{*}{ NM_138880.2 } \\
\hline & Reverse 5'- AGTGTGCCTTGGCAGTAACAGCC -3' & \\
\hline \multirow{2}{*}{ iNos } & Forward 5'- TGGTCCTGCAGGCTCACGGT -3', & \multirow[t]{2}{*}{ NM_012611.3 } \\
\hline & Reverse 5'- ACTCGAGGCCACCCACCTCC -3' & \\
\hline$\beta$-actina & $\begin{array}{l}\text { Forward 5'- TCCACCCGCGAGTACAACCTTCTT-3' } \\
\text { Reverse 5'- CGACGAGCGCAGCGATATCGT -3' }\end{array}$ & NM_031144.2 \\
\hline
\end{tabular}

O delineamento foi inteiramente ao acaso, com fatorial $2 \times 5$ (dois grupos, cinco períodos), para as análises imunoistoquímicas e fatorial $2 \times 4$ (dois grupos, quatro períodos), para o RT-PCR em tempo real. A ANOVA foi realizada e, para cada variável, foi determinada a média e o desvio-padrão. As médias foram comparadas pelo teste SNK. Diferenças foram consideradas significativas se $\mathrm{P}<0,05$.

\section{RESULTADOS}

A indução do hipotireoidismo durante todo o período gestacional foi confirmada pela concentração plasmática de $\mathrm{T}_{3}$ e $\mathrm{T}_{4}$ livre nos dias 0 e 19 de gestação e pela sintomatologia apresentada pelos animais. As ratas tratadas com PTU apresentaram concentrações menores de $\mathrm{T}_{3}$ (Tab. 2) e $\mathrm{T}_{4}$ (Tab. 3) livres em relação às do grupo controle (Tab. 2 e 3 ) e sinais clínicos de letargia e alopecia. 
Efeito do hipotireoidismo...

Tabela 2. Concentrações plasmáticas de $\mathrm{T}_{3}$ livre (média $\pm \mathrm{DP}$ ) nas ratas gestantes dos grupos controle e hipotireoideo aos 0 e 19 dias de gestação

\begin{tabular}{lcc}
\hline Período & Controle & Hipotireoideo \\
\hline Dia 0 & $2,345 \pm 0,289 \mathrm{a}$ & $1,856 \pm 0,188 \mathrm{~b}$ \\
19 dias & $1,757 \pm 0,281 \mathrm{a}$ & $1,180 \pm 0,155 \mathrm{~b}$ \\
\hline
\end{tabular}

Letras diferentes na mesma linha indicam diferença significativa $(\mathrm{P}<0,05)$

Tabela 3. Concentrações plasmáticas de $\mathrm{T}_{4}$ livre (média $\left.\pm \mathrm{DP}\right)$ nas ratas gestantes dos grupos controle e hipotireoideo aos 0 e 19 dias de gestação

\begin{tabular}{lcc} 
Período & Controle & Hipotireoideo \\
\hline Dia 0 & $1,196 \pm 0,123 \mathrm{a}$ & $0,437 \pm 0,095 \mathrm{~b}$ \\
19 dias & $0,795 \pm 0,173 \mathrm{a}$ & $0,104 \pm 0,080 \mathrm{~b}$ \\
\hline
\end{tabular}

Letras diferentes na mesma linha indicam diferença significativa $(\mathrm{P}<0,05)$

As regiões de decídua mostraram detecção de IFN $\gamma$ (Fig. 1), IL15 (Fig. 2), iNOS (Fig. 3), MIF (Fig. 4) e lectina DBA (Fig. 5) nas camadas de decídua mesometrial e antimesometrial, aos sete DG, na decídua mesometrial, aos 10 DG, e na decídua basal e na glândula metrial, aos 12, 14 e 19 DG. A detecção imunoistoquímica de IFN $\gamma$, IL15 e MIF foi nuclear e/ou citoplasmática, ao contrário da expressão do iNOS e da lectina
DBA, que foi apenas citoplasmática. Independentemente do grupo, a detecção máxima de IFN $\gamma$ (Fig. 1F), IL15 (Fig. 2F) e iNOS (Fig. $3 \mathrm{~F})$ ocorreu aos 12 DG, em comparação aos demais períodos de gestação. Já o MIF e a lectina DBA não tiveram um padrão de expressão bem definido entre os períodos e não apresentaram diferenças estatísticas entre os períodos avaliados (Fig. 4F e 5F).

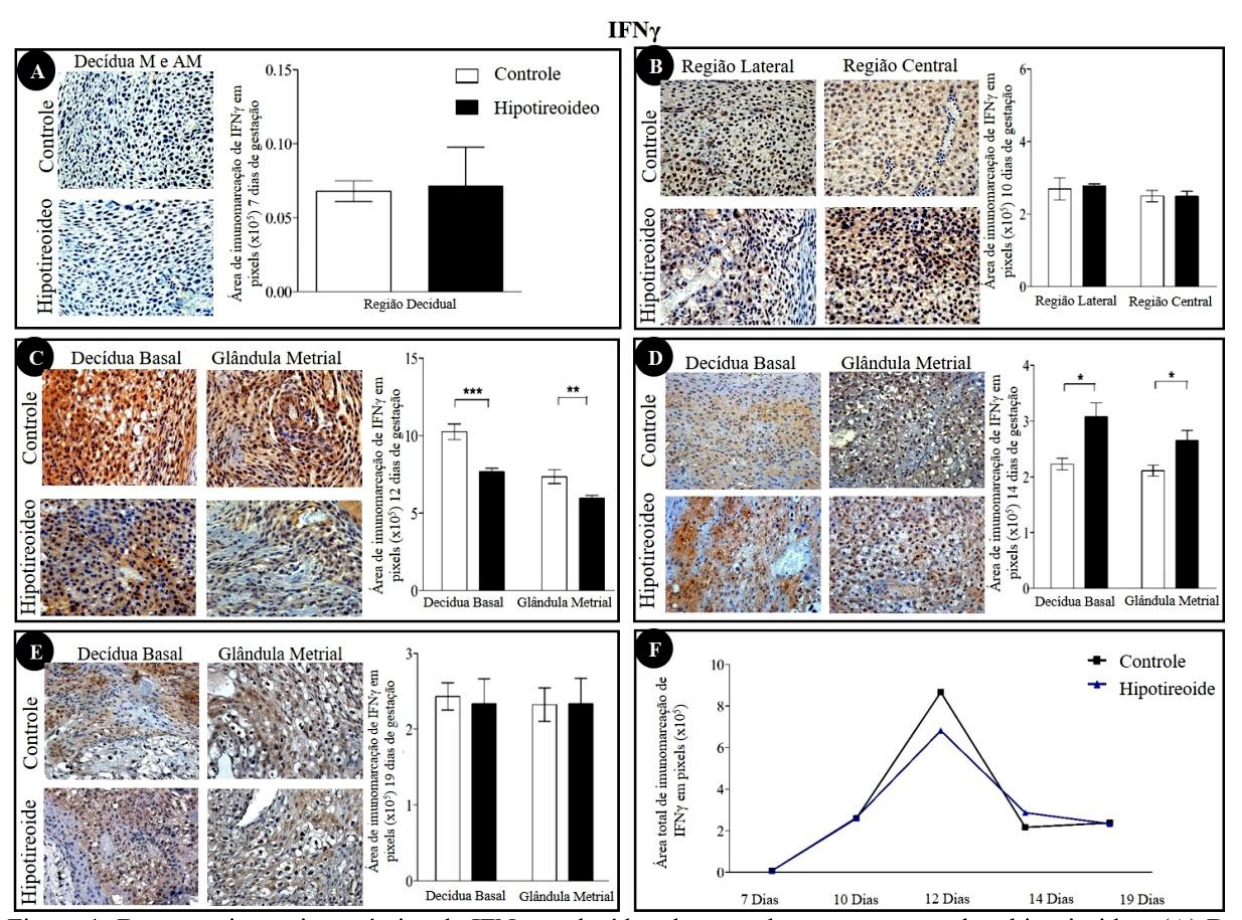

Figura 1. Detecção imunoistoquímica de IFN $\gamma$ na decídua de ratas dos grupos controle e hipotiroideo. (A) Decídua aos sete dias de gestação (DG) sem diferença entre os grupos tratado e controle. (B) Decídua aos 10 DG sem diferença significativa entre os grupos tratado e controle. (C) Decídua basal e glândula metrial aos 12 DG com redução da área de imunomarcação em ambas as áreas avaliadas. (D) Decídua basal e glândula metrial aos 14 DG com aumento da área de imunomarcação em ambas as áreas avaliadas. (E) Detecção imunoistoquímica de IFN $\gamma$ na decídua basal na glândula metrial aos 19 DG sem diferença significativa entre os grupos controle e hipotireoideo. (F) Perfil de imunomarcação de IFN $\gamma$ na decídua de ratas ao longo da gestação em cada grupo. Aos 12 DG, houve um pico da imunomarcação para IL15 em relação aos demais períodos analisados (*P<0,05; **P $<0,01 ; * * * \mathrm{P}<0,001)$. 


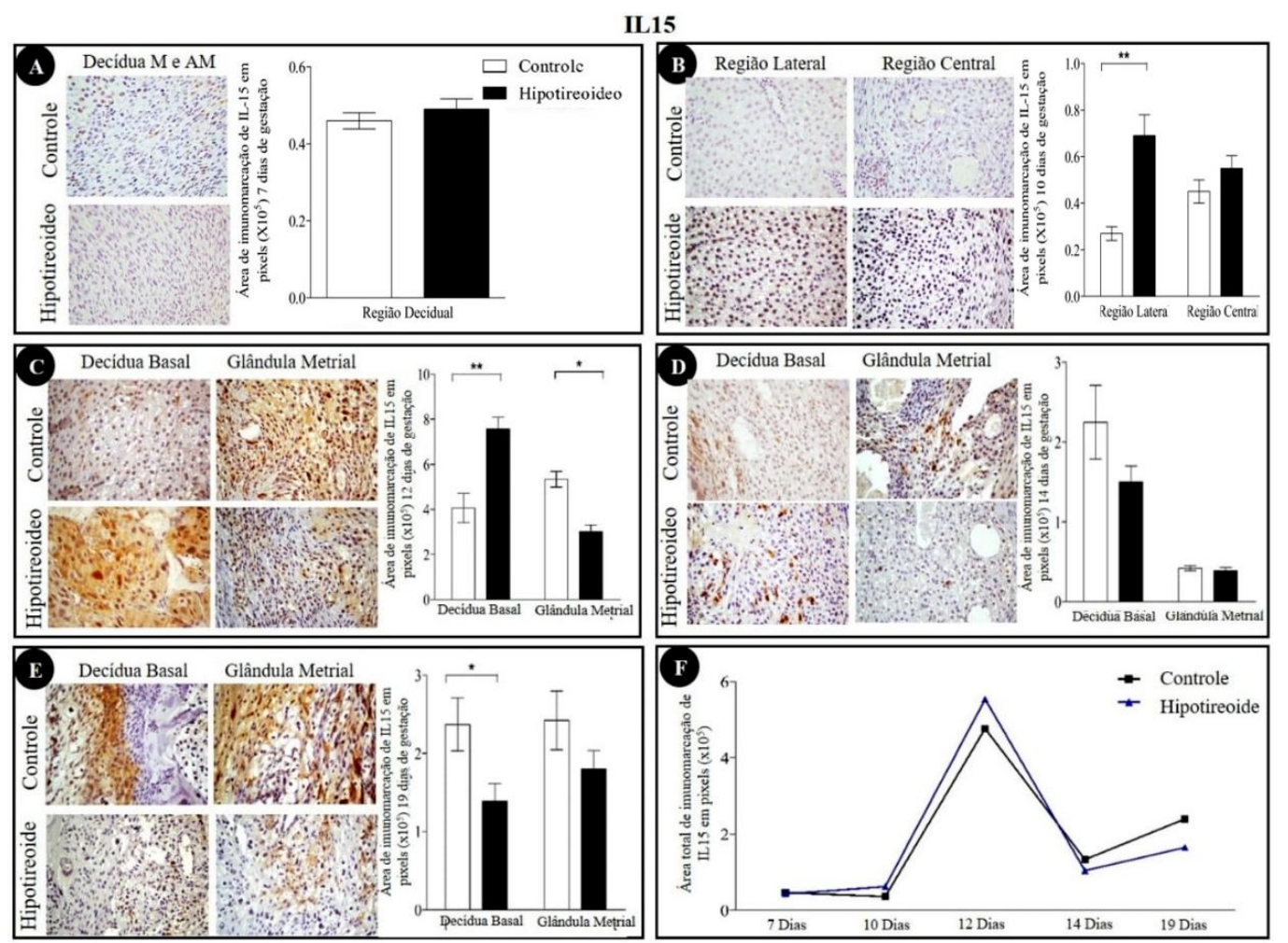

Figura 2. Detecção imunoistoquímica de IL15 na decídua de ratas dos grupos controle e hipotiroideo. (A) Decídua aos sete DG sem diferença entre os grupos controle e hipotireoideo. (B) Decídua mesometrial aos 10 DG com aumento da área de imunomarcação do grupo hipotireoideo na região lateral. (C) Decídua e glândula metrial aos 12 DG com redução da área de imunomarcação na glândula metrial e aumento na decídua basal do grupo hipotireoideo em relação ao controle. (D) Decídua e glândula metrial aos 14 DG com redução da área de imunomarcação na região de glândula metrial. (E) Decídua e glândula metrial aos 19 DG com redução da área de imunomarcação na região de decídua basal do grupo hipotireoideo em relação ao controle. (F) Perfil de imunomarcação de IL15 na decídua de ratas ao longo da gestação em cada grupo. Aos 12 DG, houve um pico da imunomarcação para IL15 em relação aos demais períodos analisados. $(* \mathrm{P}<0,05 ; * * \mathrm{P}<0,01)$.

Aos 12 DG, houve redução da imunomarcação de IFN $\gamma$ no grupo hipotireoideo $(\mathrm{P}<0,01)$ (Fig. 1C) em relação ao controle. Ao contrário, aos 14 DG, houve aumento da área de imunomarcação de IFN $\gamma$ em relação ao controle na decídua basal e na glândula metrial (Fig. 1D). Aos 10 DG, houve aumento da área de imunomarcação para IL15 na região lateral no grupo hipotireoideo em comparação ao controle (Fig. 2B; $\mathrm{P}<0,01$ ). Aos 12 dias, o aumento da área de imunomarcação se manteve no grupo hipotireoideo na região da decídua basal (Fig. 2C; $\mathrm{P}<0,01$ ). Contudo, na região da glândula metrial, houve redução no grupo hipotireoideo $(\mathrm{P}<0,01)$ (Fig. 2C). Apesar dessa redução, foi observado o pico de expressão de IL15 aos 12 DG tendo sido estatisticamente diferente dos demais períodos analisados (Fig. 2F). Aos 19 DG, entretanto, houve redução da área de imunomarcação para IL15 na região de decídua basal no grupo hipotireoideo $(\mathrm{P}<0,05)$ (Fig. 2E).

Com relação à imunomarcação para o óxido nítrico sintase induzível (iNOS), aos sete DG, observou-se aumento da área de imunomarcação na região de decídua no grupo hipotireoideo (Fig. 3A; P<0,05). Já aos 12 DG, na decídua basal e na glândula metrial, houve redução no grupo hipotireoideo da área de imunomarcação de iNOS em relação ao controle (Fig. 3C; $\mathrm{P}<0,05$ ). Apesar dessa redução, foi observado o pico de expressão de iNOS aos 12 DG tendo sido estatisticamente diferente dos demais períodos analisados (Fig. 3F), como ocorreu na IL15 e no IFN $\gamma$. Aos 14 e 19 DG, a redução da área de imunomarcação de iNOS no grupo hipotireoideo manteve-se na glândula metrial (Fig. 3D; 3E; $\mathrm{P}<0,05)$ em relação ao grupo controle. 
iNOS
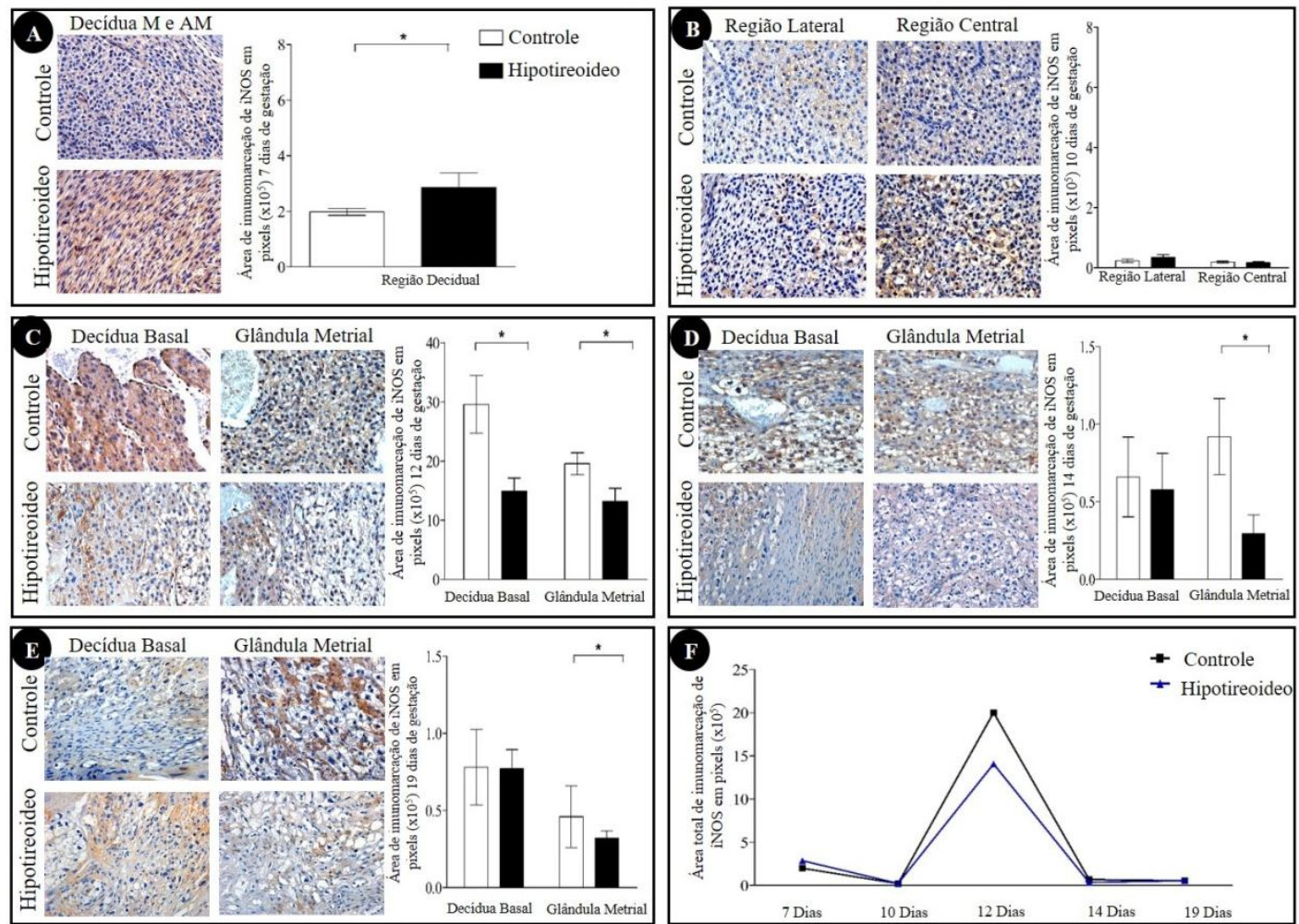

Figura 3. Deteccão imunoistoquímica de iNOS na decídua e na glândula metrial de ratas dos grupos controle e hipotiroideo. (A) Decídua aos sete DG com aumento da área de imunomarcação de iNOS na região da decídua mesometrial e antimesometrial no grupo hipotireoideo em comparação com o grupo controle. (B) Decídua mesometrial aos 10 DG sem diferença significativa entre os grupos hipotireoideo e controle. (C) Decídua e glândula metrial aos 12 DG com redução da área de imunomarcação na decídua basal e na glândula metrial do grupo hipotireoideo em relação ao controle. (D) Decídua e glândula metrial aos 14 DG, com redução da área de imunomarcação na região de glândula metrial do grupo hipotireoideo em relação ao controle. (E) Decídua e glândula metrial aos 19 DG com redução da área de imunomarcação na região da glândula metrial do grupo hipotireoideo em relação ao controle. (F) Perfil de imunomarcação de iNOS na decídua de ratas ao longo da gestação em cada grupo. Aos 12 DG, houve um pico da imunomarcação para IL15 em relação aos demais períodos analisados $(* \mathrm{P}<0,05 ; * * \mathrm{P}<0,01 ; * * * \mathrm{P}<0,001)$.

A área de imunomarcação para o MIF reduziu-se intensamente no grupo hipotireoideo aos sete DG em relação ao controle (Fig. 4A; $\mathrm{P}<0,001$ ). Aos 10 DG, o grupo hipotireoideo apresentou aumento da imunomarcação para MIF (Fig. 4B). Aos 12 DG, na decídua basal, houve aumento da imunomarcação de MIF no grupo hipotireoideo (Fig. 4C; $\mathrm{P}<0,01$ ) em relação ao controle, mas sem diferença na região da glândula metrial $(\mathrm{P}>0,05)$. Aos 14 dias, na decídua basal e na glândula metrial, observou-se aumento de MIF no grupo hipotireoideo (Fig. 4D; $\mathrm{P}<0,05$ ) em relação ao controle. Aos $19 \mathrm{DG}$, não foram observadas diferenças significativas entre grupos (Fig. 4E). Ainda com relação à expressão de MIF, observou-se que a flutuação da expressão de MIF ao longo da gestação não seguiu um padrão, com um pico de expressão, como nas marcações pelos IFN $\gamma$, IL15 e iNOS (Fig. 4F). 


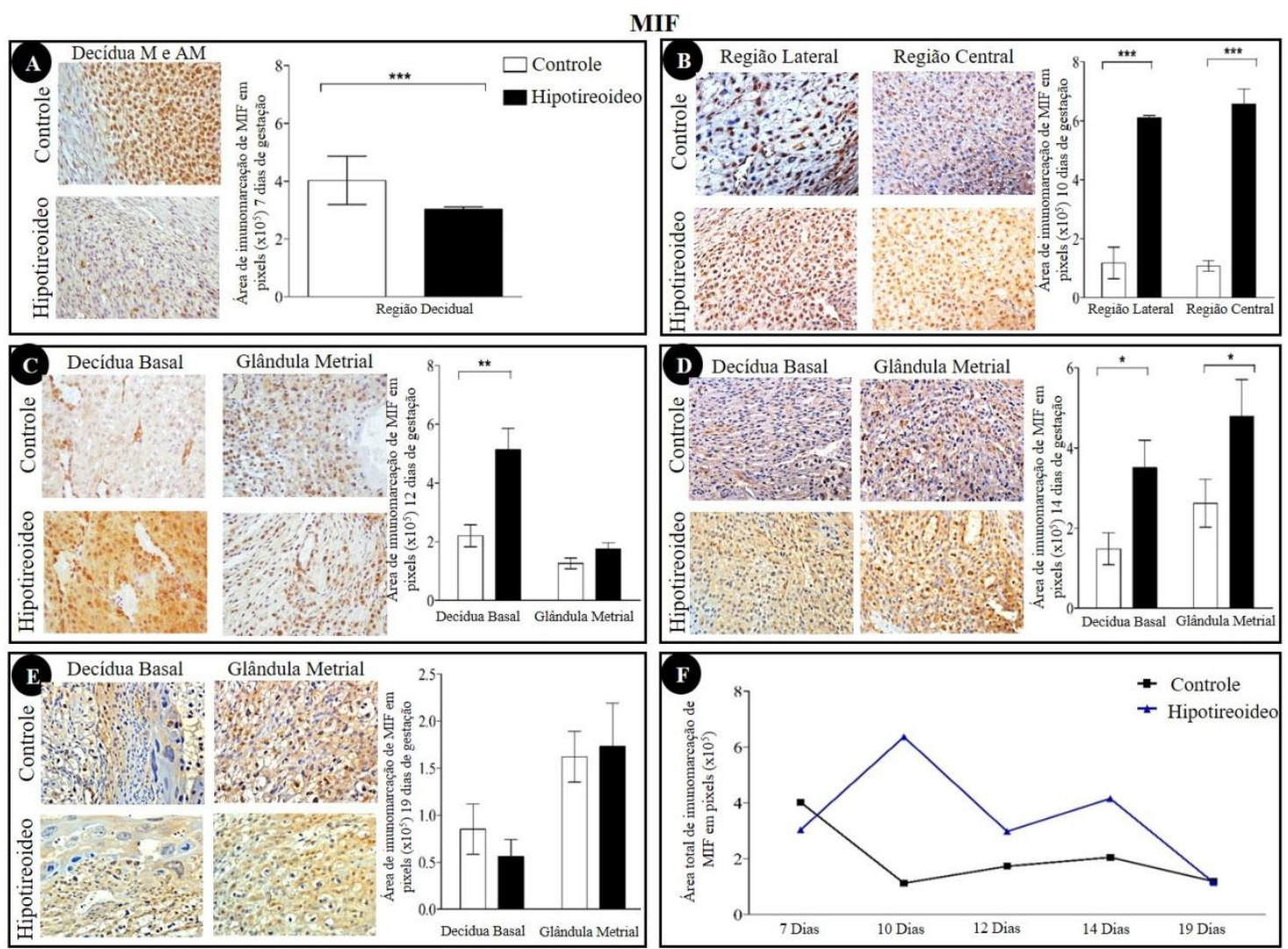

Figura 4. Detecção imunoistoquímica de MIF na decídua e na glândula metrial de ratas dos grupos controle e hipotiroideo. (A) Decídua aos sete DG com redução da área de imunomarcação de MIF na região da decídua mesometrial e antimesometrial do grupo hipotireoideo em relação ao controle. (B) Decídua mesometrial aos 10 DG com aumento da área de imunomarcação nas regiões lateral e central do grupo hipotireoideo. (C) Decídua e glândula metrial aos 12 DG com aumento da área de imunomarcação na decídua basal no grupo hipotireoideo em relação ao controle. (D) Decídua e glândula metrial aos 14 DG com aumento, da área de imunomarcação, na região de decídua basal e na glândula metrial do grupo hipotireoideo, em relação ao controle. (E) Decídua e glândula metrial aos 19 DG sem diferenças significativas entre os grupos. (F) Perfil de imunomarcação de MIF na decídua de ratas ao longo da gestação em cada grupo $(* \mathrm{P}<0,05 ; * * \mathrm{P}<0,01 ; * * * \mathrm{P}<0,001)$.

A imunomarcação para lectina DBA aos sete DG reduziu-se no grupo hipotireoideo em relação ao controle ( $\mathrm{P}<0,001)$ (Fig. 5A). Aos $10 \mathrm{DG}$, na região lateral, também houve redução da imunomarcação neste grupo para as células uNK $\operatorname{DBA}^{+}($Fig. 5B), sendo sua presença mais evidente na região central, onde há a presença da arteríola espiralada central. Nessa região, as células uNK apresentavam-se ora volumosas, ora semelhantes a linfócitos com escasso citoplasma. Nesse período da gestação, as células deciduais também expressaram lectina DBA. A expressão de lectina DBA nas células uNK foi diferenciada, forte e junto à membrana nuclear. Nesse período, foi possível visualizar as células uNKs infiltrando-se na glândula metrial e dispondo-se concentricamente ao redor dos vasos sanguíneos. Esse padrão concêntrico torna-se mais evidente aos 12 e 14 DG. Aos 14 DG, observou-se redução da área $(\mathrm{P}<0,01)$ de imunomarcação para lectina DBA no grupo hipotireoideo somente na região de decídua basal (Fig. 5D). Aos 19 DG, a marcação torna-se mais fraca e as células têm aspecto mais vacuolizado, caracterizando o processo degenerativo que ocorre comumente ao final da gestação. Nesse período, não houve diferença de imunomarcação entre os grupos (Fig. 5E). 
Efeito do hipotireoidismo...

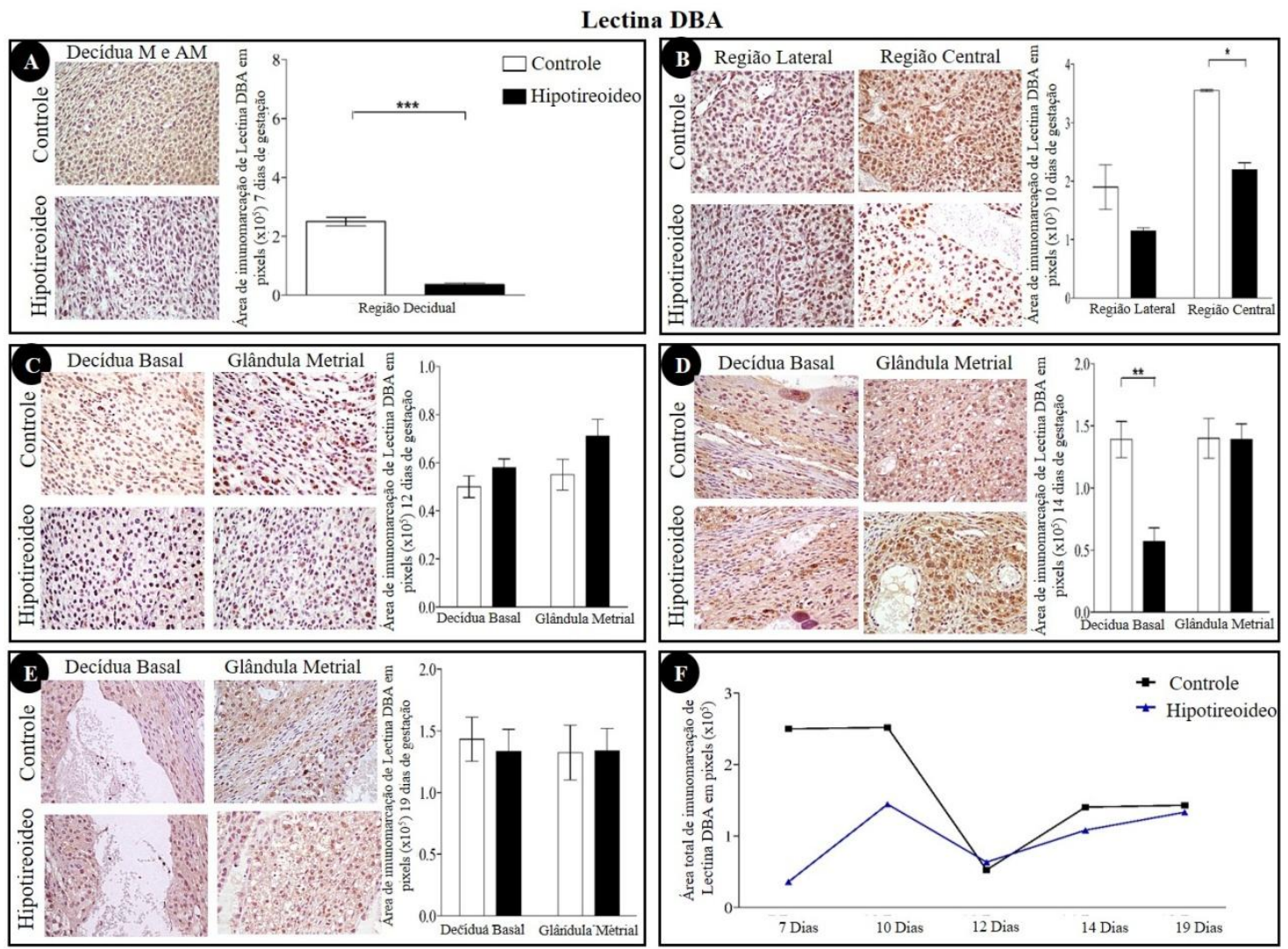

Figura 5. Detecção imunoistoquímica de lectina DBA na decídua e na glândula metrial de ratas dos grupos controle e hipotiroideo. (A) Decídua mesometrial e antimesometrial aos sete DG com redução da área de imunomarcação de lectina DBA na região da decídua mesometrial e antimesometrial do grupo hipotireoideo em relação ao controle. (B) Decídua mesometrial aos 10 DG com redução da área de imunomarcação na região central e na glândula metrial do grupo hipotireoideo. (C) Decídua basal e glândula metrial aos 12 DG sem diferença entre os grupos. (D) Decídua basal e glândula metrial aos 14 DG com redução da área de imunomarcação na região de decídua basal no grupo hipotireoideo em relação ao grupo controle. (E) Decídua basal e glândula metrial aos 19 DG sem diferenças significativas entre os grupos. (F) (F) Perfil de imunomarcação de lectina DBA na decídua de ratas ao longo da gestação em cada grupo $(* \mathrm{P}<0,05 ; * * \mathrm{P}<0,01 ; * * * \mathrm{P}<0,001)$.

Aos 10 DG, a expressão dos transcritos gênicos para Ifny (Fig. 6A; P<0,01) e iNos (Fig. 6B; $\mathrm{P}<0,01)$ reduziu-se no grupo hipotireoideo em relação ao controle. Aos 12 DG, a expressão gênica de Nos2 aumentou no grupo hipotireoideo em comparação ao controle (Fig. 6B; P<0,001), diferentemente dos 14 DG, em que sua expressão reduziu-se (Fig. 6B; $\mathrm{P}<0,05$ ). Em contrapartida, o Ifny apresentou maior expressão gênica no grupo hipotireoideo em relação ao controle aos 14 DG (Fig. 6A; P<0,05). Aos 19 dias, o hipotireoidismo reduziu a expressão de Ifn $\gamma$ (Fig. 6A; $\mathrm{P}<0,01)$ na decídua. Contudo, aumentou a expressão de iNos em relação ao controle (Fig. $6 \mathrm{~B} ; \mathrm{P}<0,01)$. 


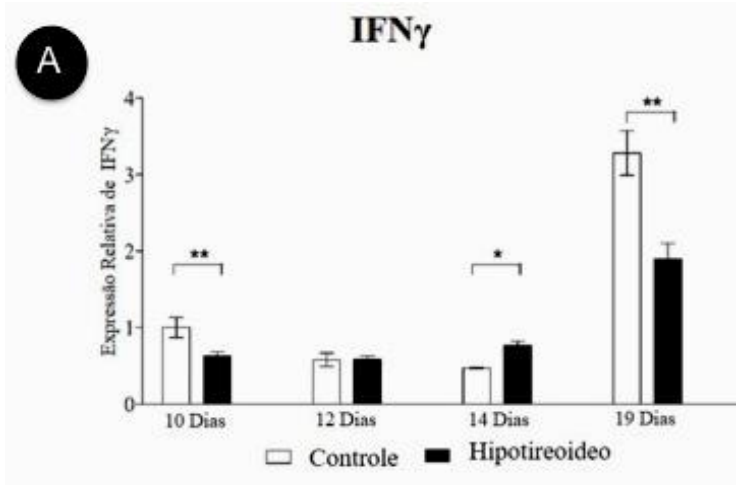

B

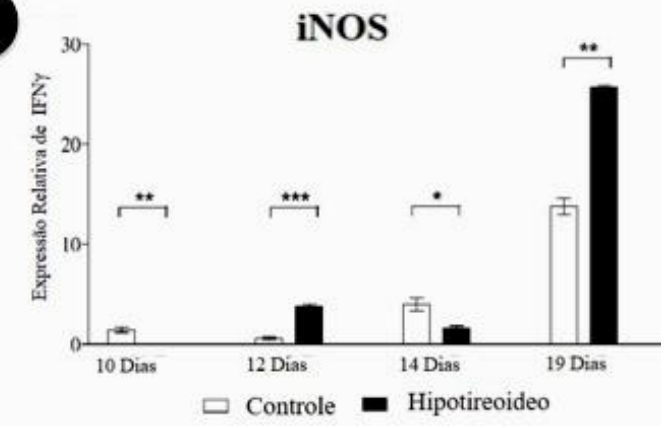

Figura 6. Expressão relativa gênica de IFN $\gamma$ e iNOS na decídua de ratas dos grupos controle e hipotiroideo aos sete, 10,12, 14 e 19 DG. (A) Expressão relativa de Ifn $\gamma$ apresentando redução no grupo hipotireoideo aos 10 DG, aumento aos 14 DG e redução aos 19 DG em relação ao grupo controle. (B) Expressão relativa de iNos apresentando redução aos 10 DG, aumento aos 12 DG, redução aos 14 DG e aumento aos 19 DG do grupo hipotireoideo em relação ao controle $(* \mathrm{P}<0,05 ; * * \mathrm{P}<0,01 ; * * * \mathrm{P}<0,001)$.

\section{DISCUSSÃO}

O hipotireoidismo materno alterou o perfil de expressão espaço-temporal dos fatores imunológicos na decídua e na glândula metrial de ratas ao longo da gestação. Embora a resposta tenha sido variável dentro do grupo, dependendo da região e do período analisados, a redução do fator anti-inflamatório iNOS e da marcação de células uNKs $\mathrm{DBA}^{+}$foi evidente no grupo hipotireoideo, o que pode comprometer não somente o desenvolvimento de um ambiente anti-inflamatório na interface materno-fetal como também o remodelamento arterial intrauterino pelas células trofoblásticas. É pertinente destacar que efeitos semelhantes foram observados no disco placentário de ratas com hipotireoidismo materno (Silva et al., 2014).

Aos sete DG, o hipotireoidismo aumentou a imunomarcação de iNOS e reduziu a imunoexpressão de MIF e a população de células
uNK $\mathrm{DBA}^{+}$. O iNOS tem efeitos antiinflamatórios, e o seu aumento na interface materno-fetal está associado ao estresse oxidativo (Leanza et al., 2007). É importante ressaltar que, nesse período gestacional, é necessário um ambiente pró-inflamatório que permita o processo de implantação embrionária e migração trofoblástica (Koga et al., 2009), sendo que o aumento da expressão de iNOS observado nos animais hipotireoideos, nesse período gestacional, pode comprometer tais processos. Além disso, a menor expressão de lectina DBA nos animais hipotireoideos sugere menor número ou diferenciação de células uNKs. Esse achado pode tanto desfavorecer o perfil imunológico da interface materno-fetal quanto prejudicar $o$ remodelamento vascular, uma vez que as células uNKs estão envolvidas nesse processo (Plaisier, 2011). O MIF é uma citocina multifuncional que tem sido relacionada, na interface materno-fetal, à angiogênese, à proliferação celular (Viganò $e t$ al., 2007; Faria et al., 2010), à supressão da apoptose e ao aumento na síntese proteica (Faria et al., 2010). Dessa forma, a redução da imunoexpressão de MIF na decídua dos animais hipotireoideos poderia explicar o retardo na diferenciação dos fibroblastos intersticiais em células deciduais, a ausência do estímulo trófico dos hormônios tireoidianos (Galton et al., 2001) e a consequente redução da área da decídua aos 10 DG (Souza et al., 2017).

Aos 10 DG, o hipotireoidismo aumentou a imunomarcação de IL15 e MIF, mas reduziu a imunomarcação das células uNK para lectina DBA, além de reduzir a expressão gênica de Ifny e iNos. Esses achados são semelhantes aos encontrados por Silva et al. (2014) no disco placentário. O IFN $\gamma$ influencia diretamente a função das células uNKs que estão envolvidas tanto na imunidade quanto na dinâmica vascular placentária e decidual (Hu e Cross, 2010). Além disso, o IFN $\gamma$ está relacionado à atividade fagocítica de macrófagos, importante para a diferenciação do trofoblasto durante o período de diferenciação do cone ectoplacentário (Leanza et al., 2007). Portanto, a expressão reduzida de Ifn $\gamma$ pode ter sido a causa do subdesenvolvimento da decídua observado por Souza et al. (2017) em animais com hipotireoidismo. O IFN $\gamma$ sintetizado pelas células uNKs interfere na função imune decidual e modifica a expressão de genes pelas células endoteliais e estromais e pelos miócitos, favorecendo o início do remodelamento vascular 
na decídua (Ashkar et al., 2000; Hu e Cross, 2010). Mas a redução do IFN $\gamma$ poderia implicar retardo do remodelamento vascular, prejudicando a vascularização decidual, e ser a causa do retardo da diferenciação dos fibroblastos intersticiais em células deciduais (Galton et al., 2001). Esses fatos conjuntamente agravariam ainda mais o desenvolvimento da decídua e justificariam o baixo peso fetal e placentário apresentado por animais com hipotireoidismo materno (Silva et al., 2012).

O aumento da IL15 na região lateral da decídua mesometrial dos animais hipotireoideos aos 10 DG pode ter ocorrido pelo fato de que é também observado, nesse mesmo período, o acúmulo de uNKs na região central de ratas gestantes, bem como sua diferenciação (Bilinsk et al., 2008). Contudo, esse acúmulo de uNKs não foi observado no grupo hipotireoideo, uma vez que houve redução das uNKs $\mathrm{DBA}^{+}$. Existem subtipos de uNKs, algumas são $\mathrm{DBA}^{-} \mathrm{e}$ outras são $\mathrm{DBA}^{+}$(Zhang et al., 2009). Tal fato pode ter ocorrido pelo aumento de células uNKs DBA; que não foram avaliadas neste estudo. A IL15, além do seu papel pró-inflamatório, também promove a mudança no fenótipo das células NK para as células uNKs, que têm morfologia e funcionalidade peculiares durante a gestação (Kitaya et al., 2003b). Contudo, a IL15 não só aumenta a proliferação e a diferenciação da uNK como também é responsável por aumentar a atividade citolítica dessas células (Clifford et al., 1999). O aumento da expressão de IL15 acima do fisiológico poderia exacerbar a atividade citolítica da uNK, prejudicando os desenvolvimentos embrionário e fetal, e ser um dos fatores pelos quais se explica a redução da migração das células trofoblásticas na decídua de ratas com hipotireoidismo (Silva et al., 2014).

Aos 12 DG, nos animais hipotireoideos, foi observada redução da imunomarcação de IFN $\gamma$ e iNOS e aumento de IL15, de MIF e da expressão gênica de iNos. Estudos anteriores demonstraram que o IFN $\gamma$, além de ativar macrófagos deciduais, na interface materno-fetal, também induz a síntese de iNOS pelos trofoblastos fetais (Hoshida et al., 2007). A redução de imunomarcação de iNOS em animais hipotireoideos foi observada aos 12, 14, e 19 DG e a redução da expressão gênica foi observada aos 10 DG. Contudo, houve períodos em que o seu aumento também foi observado no hipotireoidismo, como aos sete DG, pela imunoistoquímica, e aos 12 e 19 DG, na expressão dos transcritos gênicos. A diferença entre os resultados de RT-PCR e da imunoistoquímica para o iNOS pode ser explicada pelo fato de que o primeiro teste reflete a expressão do transcrito gênico, enquanto o segundo permite avaliar a expressão da proteína. A redução do iNOS tem sido associada à préeclâmpsia e à restrição de crescimento intrauterino (Liao et al., 1996). O tratamento de ratas gestantes com inibidor de iNOS resulta em sintomas semelhantes ao pré-eclâmpsia. Isso ocorre porque o iNOS promove o relaxamento muscular e, na sua ausência, haveria aumento da pressão dos vasos sanguíneos e da contração uterina (Liao et al., 1996). Segundo Purcell et al. (1997), o iNOS presente na placenta de ratas está relacionado aos níveis de progesterona materno. Sabe-se que ratas com hipotireoidismo materno geralmente apresentam níveis elevados de progesterona (Hatsuta et al., 2004), e esse fato pode ter favorecido a redução dos níveis de iNOS em praticamente todos os períodos gestacionais. Além disso, a progesterona é o hormônio com maior efeito na tensão vascular ao longo da gestação em ratas (Liao et al., 1996). Outro fato interessante, que corrobora os achados do presente estudo, é que macrófagos de ratas sob influência de altas doses de progesterona apresentam redução da expressão de iNOS (Miller et al., 1996).

Pesquisas anteriores realizadas pela equipe do presente trabalho demonstraram que, no disco placentário de ratas com hipotireoidismo materno, há redução de imunomarcação de IFN $\gamma$ aos 14 e 19 DG no espongiotrofoblasto e redução de transcritos gênicos aos 10 e 14 DG (Silva et $a l ., 2014)$. A redução da imunomarcação de IFN $\gamma$ nos animais hipotireoideos do presente trabalho aos 12 DG corrobora os resultados de Silva et al. (2014) e pode comprometer o desenvolvimento placentário e decidual. $\mathrm{O}$ IFN $\gamma$ influencia diretamente a função das uNKs que estão envolvidas na função imune e na dinâmica vascular placentária e decidual (Ashkar et al., 2000; Hu e Cross, 2010). Camundongos knockout para IFN $\gamma$ e seu receptor ou sem leucócitos apresentam tecido decidual subdesenvolvido (Ashkar et al., 2000). Esses indivíduos, quando tratados com IFN $\gamma$ recombinante, podem ter um remodelamento vascular mais próximo do normal e um melhor 
desenvolvimento decidual (Monk et al., 2005). Outro fato que reforça essa afirmativa é que animais com hipotireoidismo apresentam intenso comprometimento vascular na placenta e redução do peso fetal (Silva et al., 2012).

Aos 14 DG, tem-se o ponto máximo do desenvolvimento vascular da decídua e da glândula metrial (Picut et al., 2009; Plasier, 2011). Nesse período foi observado, nos animais hipotireoideos, aumento da imunomarcação de IFN $\gamma$, MIF e redução de iNOS e das células uNKs $\mathrm{DBA}^{+}$, além do aumento da expressão gênica de Ifny e redução do Nos2. O aumento do IFN $\gamma$ é oposto ao resultado observado no disco placentário de ratas com hipotireoidismo no mesmo período gestacional, nas quais há redução de expressão gênica e proteica de IFN $\gamma$ (Silva et al., 2014). Esse fato poderia ser a explicação para abortos recorrentes em algumas mulheres com hipotireoidismo subclínico (Fontana et al., 2010). Além disso, células trofoblásticas humanas cultivadas em meio com IFN $\gamma$ têm o seu crescimento inibido e apresentam alterações degenerativas (Raghupathy, 1997).

Aos 19 DG, o hipotireoidismo resultou em redução de IL15, na decídua basal, de iNOS, na glândula metrial, e de transcritos gênicos para Ifny e aumento de iNos. Nesse período há regressão da decídua basal e da glândula metrial, com presença de células uNK degeneradas (Picut et al., 2009; Souza et al., 2017). Em condições normais, há aumento de iNOS ao longo da gestação e redução ao final (Dong et al., 1998), como confirmado pelo presente trabalho. Entretanto, observou-se que o hipotireoidismo aumentou a transcrição gênica de iNos, que poderia aumentar posteriormente, mais próximo ao parto, a expressão proteica de iNOS, criando um ambiente anti-inflamatório e, dessa forma, provocar o atraso no parto observado em animais com hipotireoidismo (Hapon et al., 2003). Isso porque o iNOS promove o relaxamento da musculatura do útero durante a gestação para evitar perda embrionária e fetal, mantendo o útero quiescente (Dong et al., 1998).

\section{CONCLUSÕES}

Conclui-se que o hipotireoidismo materno altera a expressão espaço-temporal de fatores imunológicos na decídua e na glândula metrial de ratas ao longo da gestação e que a resposta à hipofunção tireoidiana é variável, dependendo da região e do período analisados. O hipotireoidismo reduz o fator anti-inflamatório iNOS e as células uNKs $\mathrm{DBA}^{+}$, principalmente entre 12 e 14 DG, período de maior remodelamento vascular e mais crítico para o desenvolvimento placentário.

\section{AGRADECIMENTOS}

Ao auxílio financeiro da Fundação de Amparo à Pesquisa de Minas Gerais (Fapemig), do Conselho Nacional de Desenvolvimento Científico e Tecnológico (CNPq) e da Coordenação de Aperfeiçoamento de Pessoal de Nível Superior (Capes).

\section{REFERÊNCIAS}

ARCURI, F.; CINTORINO, M.; CARDUCCI, A. et al. Human decidual natural killer cells as a source and target of macrophage migration inhibitory factor. Reproduction, v.131, p.175$182,2006$.

ASHKAR, A..; DI SANTO, J.P.; CROY, B.A. Interferon $\gamma$ contributes to initiation of uterine vascular modification, decidual integrity, and uterine natural killer cell maturation during normal murine pregnancy. J. Exp. Med., v.192, p.259-270, 2000.

ASHKAR, A.A.; BLACK, G.P.; WEI, Q. et al. Assessment of requirements for IL15 and INF regulatory factors in uterine NK Cell differentiantion and function during pregnancy. J. Immunol., v.171, p.2937-2944, 2003.

BILINSK, M.J.; THORME, J.G.; OH, M.J. et al. Uterine NK cells in murine pregnancy. Reprod. BioMed. Online, v.16, p.218-226, 2008.

CARTWRIGHT, J.E.; HOLDEN, D.P.; WHITLEY, G.S.J. Hepatocyte growth factor regulates human trophoblast motility and invasion: a role for nitric oxide. $B r . J$. Pharmacol., v.128, p.181-189, 1999.

CHA, J.; SUN, X.; DEY, S.K. Mechanisms of implantation: strategies for successful pregnancy. Nat. Med., v.18, p.1754-1767, 2012.

CLIFFORD, K.; FLANAGAN, A.M.; REGAN, L. $\mathrm{CD}^{+} 6^{+}$natural killer cells in women with recurrent miscarriage: a histomorphometric study. Hum. Reprod., v.14, p.2727-2730, 1999. 
COLLINS, M.K.; TAY, C.; ERLEBACHER, A. Dendritic cell entrapment within the pregnant uterus inhibits immune surveillance of the maternal/fetal interface in mice. J. Clin. Invest., v.119, p. 2062-2063, 2009.

COLUCCI, F.; BOULENOUAR, S.; KIECKBUSCH, J. et al. How does variability of immune system genes affect placentation? Placenta, v.32, p.539-545, 2011.

DONG, Y.L.; FANG, L.; GANGULA, P.R.R. et al. Regulation of inducible nitric oxide synthase messenger ribonucleic acid expression in pregnant rat uterus. Biol. Reprod., v.59, p.933940, 1998.

FARIA, M.R.; HOSHIDA, M.S.; FERRO, E.A. et al. Spatiotemporal patterns of macrophage migration inhibitory factor (Mif) expression in the mouse placenta. Reprod. Biol. Endocrinol., v.8, p.95-103, 2010.

FONTANA, V.A.; SANCHEZ, M.; CEBRAL, E. et al. Interferon- $\gamma$ inhibits metalloproteinase activity and cytotrophoblast cell migration. $J$. Reprod. Immunol., v.64, p.20-26, 2010.

GALTON, V.A.; MARTINEZ, E.; HERNANDEZ, A. et al. The type 2 iodothyronine deiodinase is expressed in the rat uterus and induced during pregnancy. Endocrinology, v.142, p.2123-2128, 2001.

GELLERSEN, B.; BROSENS, I.A.; BROSENS, J.J. Decidualization of the human endometrium : mechanisms, functions, and clinical perspectives. Semin. Reprod. Med., v.25, p.445-453, 2007.

HAPON, M.B.; SIMONCINI, M.; VIA, G. et al. Effect of hypothyroidism on hormone profiles in virgin, pregnant and lactating rats, and on lactation. Reproductin, v.126, p.371-382, 2003.

HATSUTA, M.; ABE, K.; AMURA, K. et al. Effects of hypothyroidism on the estrous cycle and reproductive hormones in mature female rat. Eur. J. Pharmacol., v.486, p.343-348, 2004.

HOSHIDA, M.S.; GORJÃO, R.; LIMA, C. et al. Regulation of gene Expression in Mouse Trophoblast Cells by Interferon-gamma. Placenta, v.28, p.1059-1072, 2007.

HU, D.; CROSS, J.C. Development and function of trophoblast giant cells in the rodent placenta. Int. J. Develop. Biol., v.54, p.341-354, 2010.
KILBY, M.D.; BARBER, K.; HOBBS, E. et al. Thyroid hormone action in the placenta. Placenta, v.26, p.106-113, 2005.

KITAYA, K.; NAKAYAMA, T.; OKUBO, T. et al. Expression of macrophage inflammatory protein-1 $\beta$ in human endometrium: its role in endometrial recruitment of natural killer cells. $J$. Clin. Endocrinol. Metab., v.88, p.1809-1814, 2003a.

KITAYA, K.; YASUDA, J.; NAKAYAMA, T. et al. Effect of female sex steroids on human endometrial CD16 neg CD56 bright natural killer cells. Fertil. Steril., v.79, Suppl.1, p. 730-734, 2003b.

KOGA, K.; ALDO, P.B.; MOR, G. Toll-like receptors and pregnancy: trophoblast as modulators of the immune response. J. Obstet. Gynaecol. Res., v.35, p.191-202, 2009.

LEANZA, E.C.; HOSHIDA, M.S.; COSTA, A.F. et al. Signaling molecules involved in IFNgamma-inducible nitric oxide synthase expression in the mouse trophoblast. Am. J. Reprod. Immunol., v.58, p.537-546, 2007.

LIAO, Q.P.; BUHIMSCHI, I.A.; SAADE, G. et al. Regulation of vascular adaptation during pregnancy and post-partum: effects of nitric oxide inhibition and steroid hormones. Hum. Reprod., v.11, p.2777-2784, 1996.

MILLER, L.; ALLEY, E.W.; MURPHY, W.J. et al. Progesterone inhibits inducible nitric oxide synthase gene expression and nitric oxide production in murine macrophages. J. Leuk. Biol., v.59, p.442-450, 1996.

MONK, J.M.; LEONARD, S.; McBEY, B.A. et $a l$. Induction of murine spiral artery modification by recombinant human interferon-gamma. Placenta, v.26, p.835-838, 2005.

PICUT, C.A.; SWANSON, C.L.; PARKER, R.F. et al. The metrial gland in the rat and its similarities to granular cell tumors. Toxicol. Pathol., v.37, p.474-480, 2009.

PLAISIER, M. Decidualisation and angiogenesis. Best Pract. Res. Clin. Obstet. Gynaecol., v.25, p.259-271, 2011.

PURCELL, T.L.; BUHIMSCHI, I.A.; GIVEN, R. et al. Inducible nitric oxide synthase is present in the rat placenta at the fetal-maternal interface and decreases prior to labour. Mol. Hum. Reprod., v.3, p.485-491, 1997. 
RAGHUPATHY, R. Th1-type immunity is incompatible with successful pregnancy. Immunol. Today, v.18, p.478-482, 1997.

REYNOLDS, L.P.; BOROWICZ, P.P.; CATON, J.S. et al. Uteroplacental vascular development and placental function: an update. Int. J. Devel. Biol., v.54, p.355-365, 2010.

SILVA, J.F.; OCARINO, N.M.; SERAKIDES, R. Maternal thyroid dysfunction affects placental gene profile of inflammatory mediators and the intrauterine trophoblast migration kinetics. Reproduction, v.147, p.803-816, 2014.

SILVA, J.F.; OCARINO, N.M.; SERAKIDES, R. Placental angiogenic and hormonal factors are affected by thyroid hormones in rats. Pathol. Res. Pract., v.211, p.226-34, 2015.

SILVA, J.F.; VIDIGAL, P.N.; GALVÃO, D.D. et al. Fetal growth restriction in hypothyroidism is associated with changes in proliferative activity, apoptosis and vascularisation of the placenta. Reprod. Fertil. Devel., v. 24, p. 923931, 2012.

SOARES, M.J.; CHAKRABORTY, D.; RUMI, M A.K. et al. Rat placentation: an experimental model for investigating the hemochorial maternal-fetal interface. Placenta, v.33, p.233$243,2012$.

SOUZA, C.A.; SILVA, J.F.; SILVA, C.L.R. et al. Thyroid hormones affect decidualizaion and angiogenesis in the decidua and metrial gland or rats. Pesqui. Vet. Bras., v.37, p.1002-1014, 2017.
TWIG, G.; SHINA, A.; AMITAL, H. et al. Pathogenesis of infertility and recurrent pregnancy loss in thyroid autoimmunity. $J$. Autoimmun., V.38, p.275-281, 2012.

VASILOPOULOU, E.; LOUBIÈRE, L.S.; LASH, G.E. et al. Triiodothyronine regulates angiogenic growth factor and cytokine secretion by isolated human decidual cells in a cell-type human decidual cells in a cell-type specific and gestational age-dependent manner. Hum. Reprod., v.1, p.1-12, 2014.

VIGANÒ, P.; CINTORINO, M.; SCHATZ, F. et al. The role of macrophage migration inhibitory factor in maintaining the immune privilege at the fetal-maternal interface. Semin. Immunopathol., v.29, p.135-150, 2007.

YE, W.; ZHENG, L.M.; YOUNG, J.D.E. et al. The Involvement of Interleukin (IL) -15 in regulating the differentiation of granulated metrial gland cells in mouse pregnant uterus. $J$. Exp. Med., v.184, p.2405-2410, 1996.

ZHANG, J.; CHEN, Z.; SMITH, G.N. et al. Natural killer cell-triggered vascular transformation: maternal care before birth? Cell. Mol. Immunol., v.8, p.1-11, 2011.

ZHANG, J.H.; YAMADA, A.T.; CROY, B.A. DBA-lectin reactivity defines natural killer cells that have homed to mouse decidua. Placenta, v.30, p.968-973, 2009. 